\title{
Simulation of Mechanical Behaviour in Milling and Polishing of Dental Polymeric (resin) Composites
}

\author{
GHEORGHE VOICU, GABRIEL ALEXANDRU CONSTANTIN*, ALEXANDRU SARACIN \\ University Politehnica of Bucharest, Faculty of Biotechnical Systems Engineering, Department of Biotechnical Systems, \\ 313 Splaiul Independentei Str., 060042, Bucharest, Romania
}

\begin{abstract}
Dental resin composites have a wide applicability in the dental field. They exhibit their own chemical composition that imparts certain physico-mechanical properties. The machining of the pieces of these composites must be sufficiently light, withoutaffecting their strength. For processing these parts, respectively of the dental work, is used or carbide burs, or diamond burs, depending on the mechanical strength of the composite. To determine composite behaviour under action of the conical finishers was simulated their behaviour in specific simulation programs. As a result, stress concentrators may appear from the first processing which may affect the later resistance of the piece or dental work.
\end{abstract}

Keywords: finite element analysis, dental, biocomposite material, polishing process

Composite resins have a wide range of uses in dentistry, from direct restorations, recovering fractured teeth, until tooth decay with periodontitis.

Dental composites consist of an organic component based on acrylic compounds and an inorganic component (filler) which consists of a mixture of glass-like powders, such as: silicon oxide, aluminium, quartz, barium borosilicate. Thanks to the organic phase, composite materials adhere chemically to enamel and dentin, is necessary, how ever, and a binding agent. For this reason, the dental biocomposite still contains a coupling agent and a light activated initiator/accelerator system [1].

By mixing these two components, similar properties to dental hard tissues are obtained, regarding hardness, strength, elasticity, thermal and chemical isolation of dental pulp, texture, translucency and color. The polymerization process is crucial for the properties of prosthodontic devices [1].

Dental composites can be classified into several categories: 1)nanofilled composites with filler size 0.002$0.075 \mu \mathrm{m}$, and $78.5 \%$ volume of filler; 2 ) hybrid composites with filler size $0.2-3.0 \mu \mathrm{m}$, and $60-70 \%$ volume of filler; 3) microfilled composites $0.04-50 \mu \mathrm{m}$, and $32-50 \%$ volume of filler; 4) packable microfilled composites $0.4-20 \mu \mathrm{m}$, and $80 \%$ volume of filler; 5) flowable composites $0.2-3.0 \mu \mathrm{m}$, and $42-62 \%$ volume of filler [2].

Regarding composites based on bioactive calcium phosphate (amorphous calcium phosphate) $40 \%$, hybridized with zirconium, their mechanical properties (the biaxial flexure strength and the degree of conversion) can be modified by combining with ternary resins 2,2-bis[ $p$ (2 -hydroxy-3 -methacryloxypropoxy) phenyl]propane (Bīs-GMA) / trietthylene glycol dimethacrylate (TEGDMA) / $X$ (where $X$ being a neutral or acidic comonomer), especially those in which it is used acidic comonomers. Still, the addition of bioactive calcium phosphate and the exposure of composite samples to aqueous media can significantly reduce the values of biaxial flexure strength [3].

Use of fibers as filler material in dental composites based on resins has the main purpose of increasing the strength of the material. Effective fiber reinforcement depends on several factors, including the length, shape, orientation and concentration of the fiber in the resin matrix [4]. For fibers to strengthen efficiently a polymeric matrix, it is essential that stress transfers to be carried out from the polymeric matrix to the fibers, which can only be ensured if the length of the reinforcing fibers is equal or greater than the critical fiber length [5]. How ever, there is a limit on the amount of filler (whatever it is) which can be incorporated into the polymer matrix.

Dental composites are generally classified Depending on their activation and response particle size / type and distribution of filler materials. After activation mode, they can be chemically activated or light activated, while after the distribution and size of the filling they may be of particle size $1-50 \mu \mathrm{m}$ and filler content $60-80 \%$ (by weight), with dimensions of $0.01-0.1 \mu \mathrm{m}$ and filler content $30-60 \%$, hybrid composites (with conventional size filling 75\% and $8 \%$ submicron size) and nanocomposites (with the particle size of the filler between 0.1-100 nm) $[6,7]$.

Properties of dental polymer composites refers primarily to: the polymerisation shrinkage, the water sorption, the degree of conversion (from polymer to monomer) [8], the bond strength (or adhesion force), hardness [9], the fatigue strength [10], the wear resistance [11].

So, the polymerisation shrinkage is due to, firstly, to a decrease in the distance between atoms, as well as reducing the free volume $[12,13]$.

Phenomena of sorption and solubility can lead to unwanted consequences in a dental resin composite and a shortening of the life of dental restorations [14]. Are adversely affected bending strength, tensile strength, modulus of elasticity and wearing out resistance [15].

Dimethacrylate monomers used in dental restoration composites shows a degree of conversion between 55\% and $75 \%$ under conventional irradiation conditions [16] .

The bonding systems must allow adhesives to bind both to tooth enamel and dentin. Were developed, so, adhesive systems including hydrophilic monomers allowing proper adherence to dental surfaces. Adhesive systems of etchand-rinse are currently most used for soldering [17].

Also, the hardness of dental resin composites increases with an increase in fill volume $[18,19]$. It is stated that the 
dental resin composites containing round filler particles shows a higher hardness compared to composites with particulate fillings in irregular shape or with composites of mixtures of pre-polymerized materials [20]. It is very likely that fibrous composites to show a slightly higher hardness, although this is notnecessarily due to the presence of fibers [21].

Wearing outcan be classified into the adhesive, abrasive, wearing out due to fatigue and wearing out due to the chemical action of the environment. Wearing out that appears in the mouth is a combination of all types of wearing's out, rather than any type [22].

Due to the environment of use (the oral environment), dental biomaterials are subject to saliva action (strongly corrosive environment), being surrounded by microorganisms and food waste. They are subject to a continuous bacterial degradation process, to strong and intermittent mechanical forces. In addition to mechanical and chemical resistance, biomaterials should not contain toxic diffusible elements in the general circulation.

Experimental results on four dental filling materials (a nano-filled universal composite, a back-filling composite with lightw eight reinforcement, a tooth-coloured polyacid modified composite resin (compomer) and a coloured compomer indicated in restorations of deciduous teeth, shows that dental filling materials presents different behaviours for the same erosive conditions. This suggests that erosive wear resistance of direct dental restorations may influence their longevity under intraoral acid conditions [23].

Fatigue is a form of dental composite structure failure which occurs when it is repeatedly subjected to variable and dynamic loads, such as mastication forces [24]. Fatigue resistance of a resin composite varies according to its composition and can be improved by adding urethane dimethacrylate [25].

Restorative dental compositions show values of compressive fracture strength between257-410 MPa, while for the compressive fatigue strength values fall between 172-240 MPa. The tested composite materials that show ed these values had a fill load between 75/64 - 82/60 (wt\%/ vol\%) and a fill size between 0.04-0.2 - 0.19-3.3 $\mu \mathrm{m}$, fits between the type micro-hybrid (filled with zirconia-silica) and type micro-filled hybrid (filled with barium glass or coloidal silica) [26].

For resin based composites, choosing the finishing method, after photopolymerization, is a particularly important issue with regard to the roughness and surface gloss $\left(\mathrm{Gs}\left(60^{\circ}\right)\right)$. has determined that finishing with a superfine diamond bur leads to the most rough surface and almost complete loss of gloss for two resin composites having filler size of $3.0 \mu \mathrm{m}$ (hybrid composite), respective $0.2 \mu \mathrm{m}$ (submicron composite). However, the composite material has a significant effect on the surface gloss, but not the roughness of the surface. To obtain a proper roughness of the composite surface it is also important to choose finishers and the order in which they are used. If you are first using a diamond particle finisher of $25 \mu \mathrm{m}$, the surface of the composite is harshing, creating deep cuts that can not be easily removed even when using later finishing with zirconium oxide particles of $17 \mu \mathrm{m}$, especially for composites with the size of the $3 \mu \mathrm{m}$. If after finishing with diamond burs with granules of $25 \mu \mathrm{m}$ are used finishers with diamond grains of $6 \mu \mathrm{m}$, then the roughness of the surface is likely to decrease, but this depends on the size of the composite filler. This roughness only decreased to the size of the fill of $0.2 \mathrm{~mm}$ [27].
The ruggedness of a restoration is directly related both on restoration composite, but also on the finishing and polishing tools [28]. Finishing procedures for restorative composite resins can be achieved with various tools. From a clinical point of view, the most used finishing tools are carbide burs and diamond burs [29]. Finishing with diamond burs varies depending on the granulation, distribution and shape of the abrasive [30]. Harshness of surface increase with the increase of abrasive granulation of polishing tool [28]. For a diamond finishing tool to be effective, the abrasive granulation to be tougher than the restoring material of the restoration composite [31]. Carbide finishing burs may vary depending on the number of blades [32]; the higher the number of blades, the more the processed surface is more uniform and smoother. The choice of instrument may depend, at the same time, of resin composite used. Hybrid resins are recommended for use of carbide burs, and for micro-filled resins it is recommended to finish with diamond burs [30, 33]. May be used, however, successively different finishing tools to obtain a finer surface [34].

In this paper we aim to make the dynamic analysis through the finite element method of four types of bio composite materials used in dental techniques.

\section{Experimental part}

Material and method

The main factors on which the dental technique concentrates are the correct choice of materials and how they are processed. The lifetime of the materials used does not depend only on how they are used, but also how they are initially processed. In the case of milling / polishing, microfractures may appear in the structure of the material, leading to a decrease in its lifetime. This requires a serious verification of the processing procedure of processed materials. In figure 1 the methodology for analysis with finite elements is presented, for the workpiece which is processed by polishing.

\section{A. Parametric three-dimensional modelling of dental bur and of workpiece}

Dental bur together with the workpiece were initially modelled three-dimensionally using the parameterized design program SolidWorks Premium 2016 S.P. 0.0, installed on a laptop ASUS model K55V, which contains a processor Intel Core i5-3210M, $2.5 \mathrm{GHz}$, a video card NVIDIA GeForce GT 630M with its own memory of $2 \mathrm{~Gb}$, RAM memory of the laptop being of $8 \mathrm{~Gb}$. In figure 2 are views of dental bur used in the analysis, in figure 3 are views of the workpiece, and in figure 4 the SolidWorks software interface is presented.

\section{B. Dynamic simulation of the polishing process}

After drawing and assembling the pieces (in Assembly module), the milling / polishing process was simulated using the kinematic and dynamic analysis module of the program used - Motion Study. For simulation the dental bur was considered inclined with $9.7^{\circ}$ with respect to the vertical axis for the entire polishing surface to come into contact with the workpiece at the same time. Also, the dental bur has both a translational motion given by a linear motor (with velocity of $1.35 \mathrm{~mm} / \mathrm{s}$ ) which causes her to approach to the workpiece and it tends to penetrate it, as well as a rotary motion given by a rotary motor. Thus, the motion law of the rotary motor used in the dynamic simulation is presented in figure 5 .

The rotary motor was placed on the dental bur shaft (fig. 4) and was set to increase its steady speed until it 
PARAMETERIZED THREE-DIMENSIONAL MODELING OF THE DENTAL BUR AND WORKPIECE

- Modeling the parts of the polishing process in the "Parts" module of the parameterized design program used

- Assembling parts through geometric relationships between faces, edges, or vertexes of parts in the "Assembly" module

\section{DYNAMIC SIMULATION OF THE POLISHING PROCESS}

- Putting the assembly in the "Motion Study" module

- Specify the location and parameters of the elements that influence the motion: rotary motor (speed, motion law), linear motor (velocity), define the contact between the dental bur and workpiece

- Calculating the parameters of the dental bur motion
Fig. 1. The methodology for analysis with finite elements of workpiece

\section{WORKPIECE FINITE ELEMENTS ANALYSIS}

- Transfer the results of dynamic analysis to the finite element analysis module ("Simulation")

- Representation of reaction force graphs and frictional force relative to time in order to analyze the results and determine their maximum value

- Choosing the component undergoing finite element analysis (workpiece)

- Finite element meshing of analyzed components

- Performing a static simulation on selected elements with dynamic analysis loads

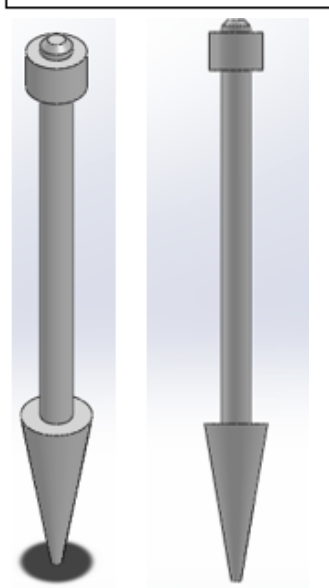

Fig. 2. Views of dental bur
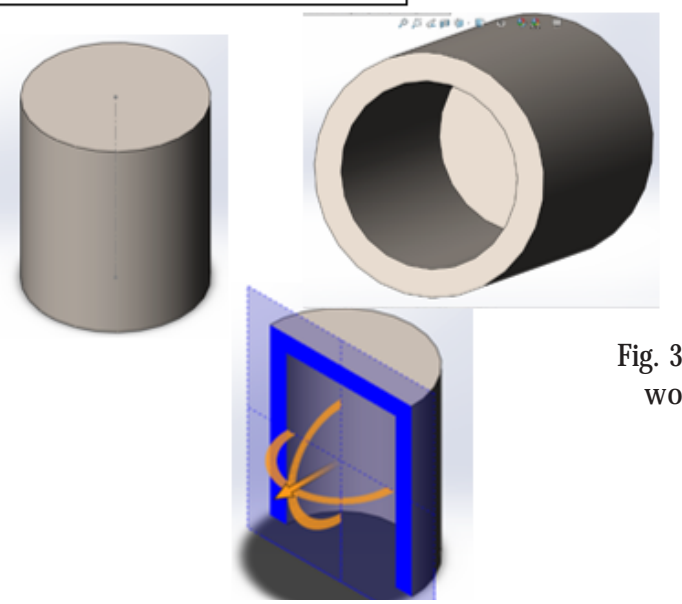

Fig. 3. Views of workpiece

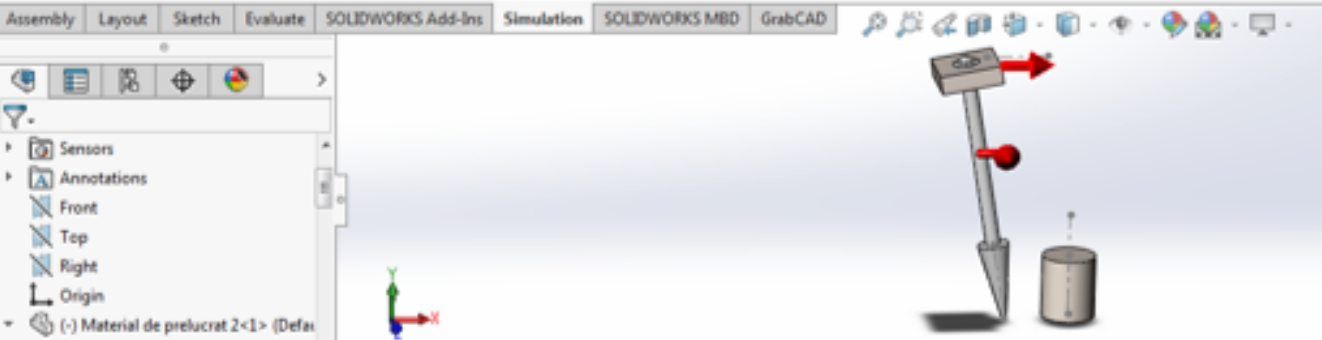

Fig. 4. The SolidWorks software interface (Motion

[17 Mees in Smulare innerices c"

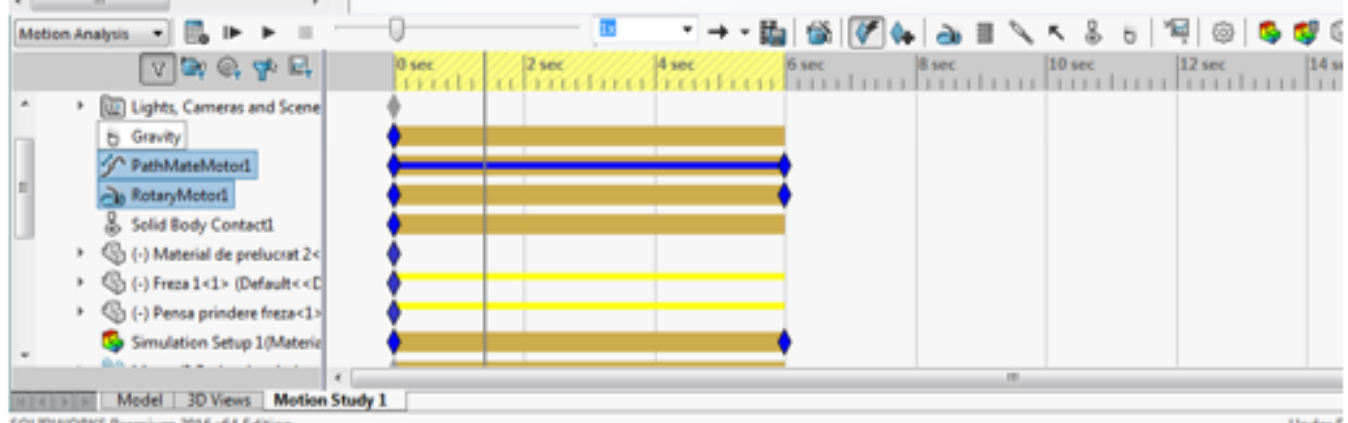

Study module)

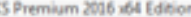

reached the nominal speed. Thus, for the move, the option Data Points was selected making settings as at the time $t$ $=0 \mathrm{~s}$, speed to be $0 \mathrm{rot} / \mathrm{min}$, at the moment $\mathrm{t}=1 \mathrm{~s}$ speed to be of $6000 \mathrm{rot} / \mathrm{min}$ (a point on the shaft to rotate 36000 $\%$, at moment $\mathrm{t}=2 \mathrm{~s}$ speed to be $12000 \mathrm{rot} / \mathrm{min}(72000$
$0 / \mathrm{s})$, at $\mathrm{t}=3 \mathrm{~s}$ speed to be $18000 \mathrm{rot} / \mathrm{min}(108000 \% \mathrm{~s})$, at $\mathrm{t}$ $=4 \mathrm{~s}$ speed to be $24000 \mathrm{rot} / \mathrm{min}(144000 \% \mathrm{~s})$, at $\mathrm{t}=5 \mathrm{~s}$ speed to be $30000 \mathrm{rot} / \mathrm{min}(180000 \% \mathrm{~s})$ and at $t=6 \mathrm{~s}$ speed to be $30166 \mathrm{rot} / \mathrm{min}(181000 \% / \mathrm{s})$, according to figure 5. For the interpolation, the mathematical model Akima 


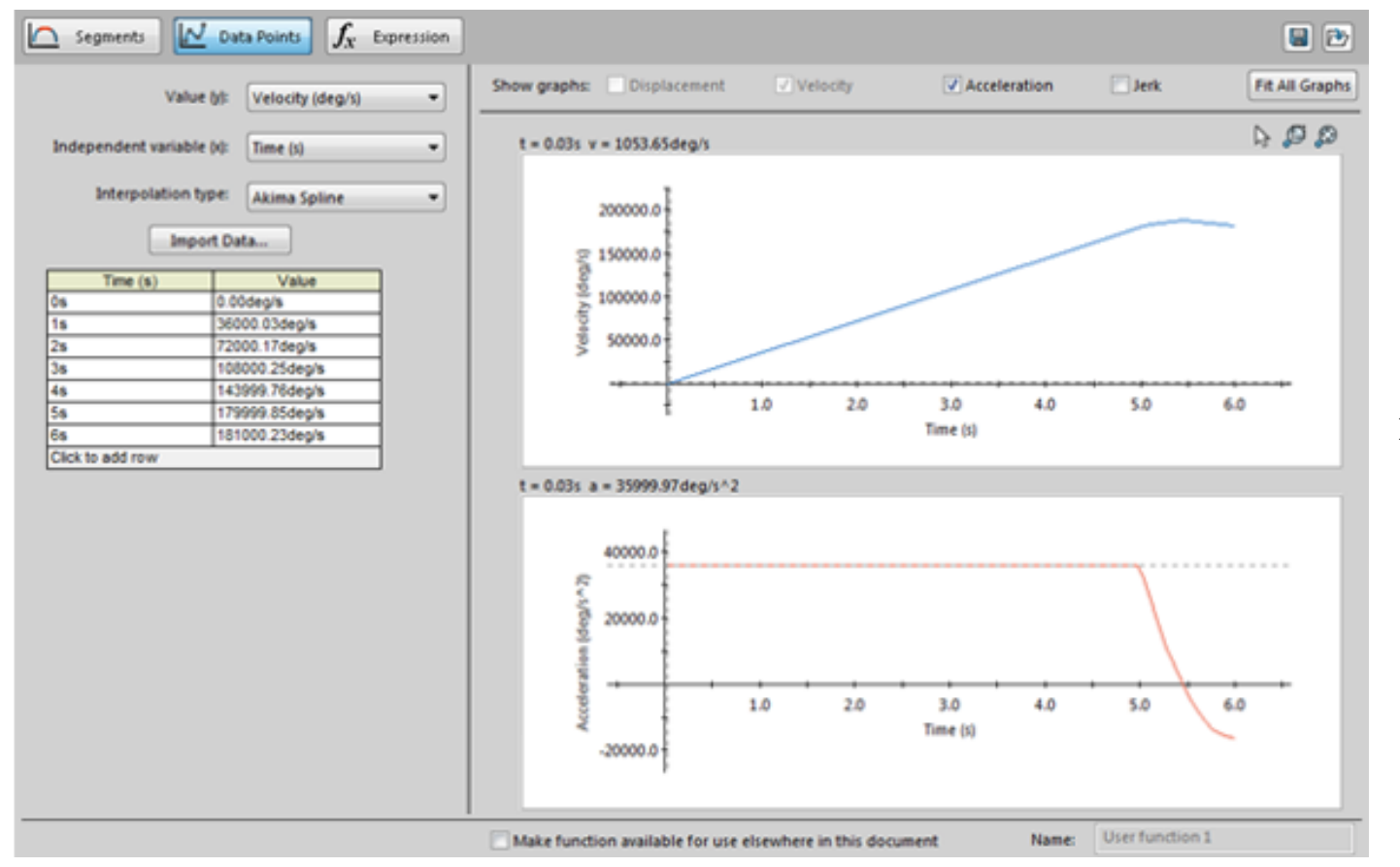

Fig. 5. The rotary motor motion law used in dynamic simulation

Spline was chosen, integrated into the dynamic analysis module.

After performing the dynamic simulation, the software has recorded in its own database the values of all loads that act on the components of the dynamic analysis.

\section{Finite Element Analysis of the workpiece}

After performing the dynamic simulation of the milling / polishing process, following the variation graphs of the reaction force and the frictional force betw een dental bur and workpiece in time, the moment at which the maximum value of these forces is recorded was determined. Determining the moments at which maximum loads arise it was possible to pass at the finite element analysis into the Simulation module of the software used.

In this module a static analysis with finite elements was made, the loads on the workpiece being imported from the dynamic analysis module (Motion Study). After meshing the workpiece was run the simulation.

\section{Results and discussions}

After performing the dynamic analysis, SolidWorks software automatically plotted the variation graphs pf reaction force and friction force over time (fig. 6 and fig.7).

From the two variation graphs we can see that the maximum values of the two forces are attained at the time $t=5.24 \mathrm{~s}(3390.5 \mathrm{~N}$ for the friction force and $17288 \mathrm{~N}$ for the reaction force). Thus, loads from this moment of time were imported into the Finite Element Analysis module, with their values being performed the static analysis.

The meshed model, as well as mesh details are presented in figure 8.

Four types of biocomposite materials were used in the analysis (Solidex, Artglass, BelleGlass and Targis), their characteristics, taken from the specialty literature, being presented in the table 1.

After meshing the model was run the simulation. Following the simulation, the design program provided the graphical results; the geometric model is divided into different colour zones, each area comprising the region of

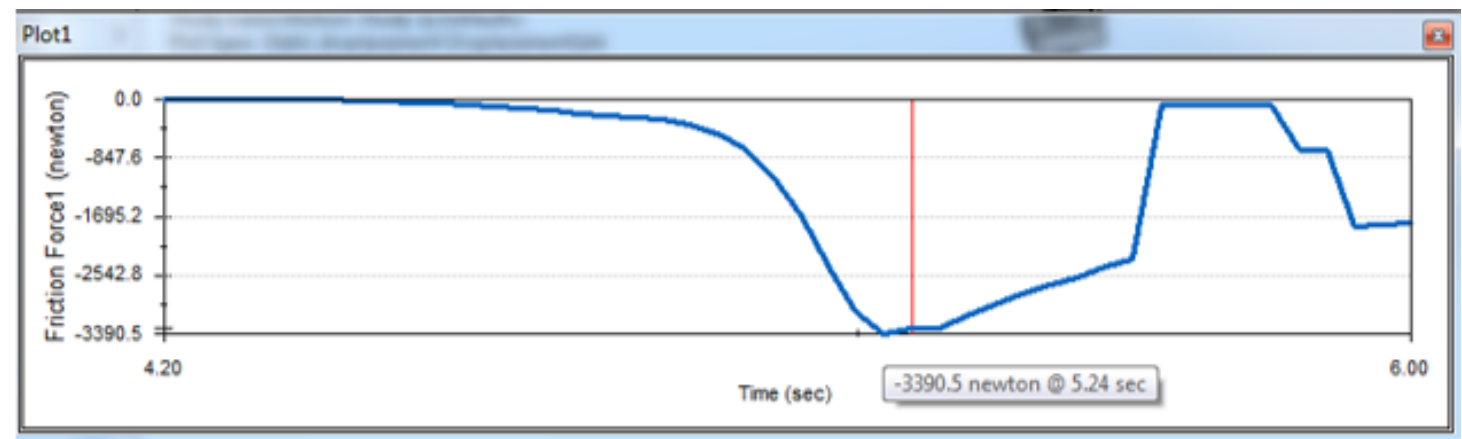

Fig. 6. Variation of friction force versus time

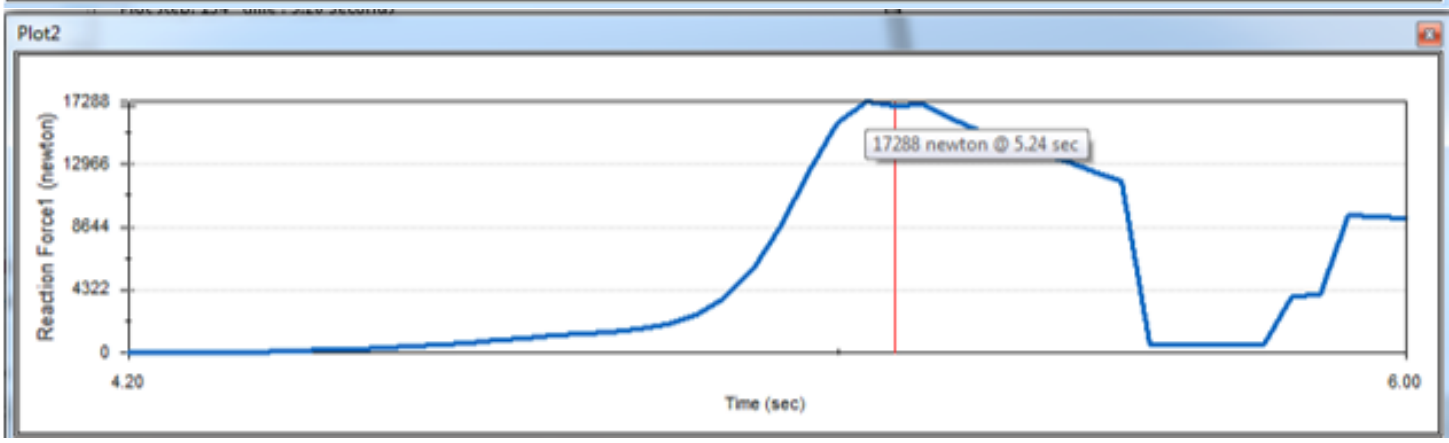

Fig. 7. Variation of reaction force versus time 

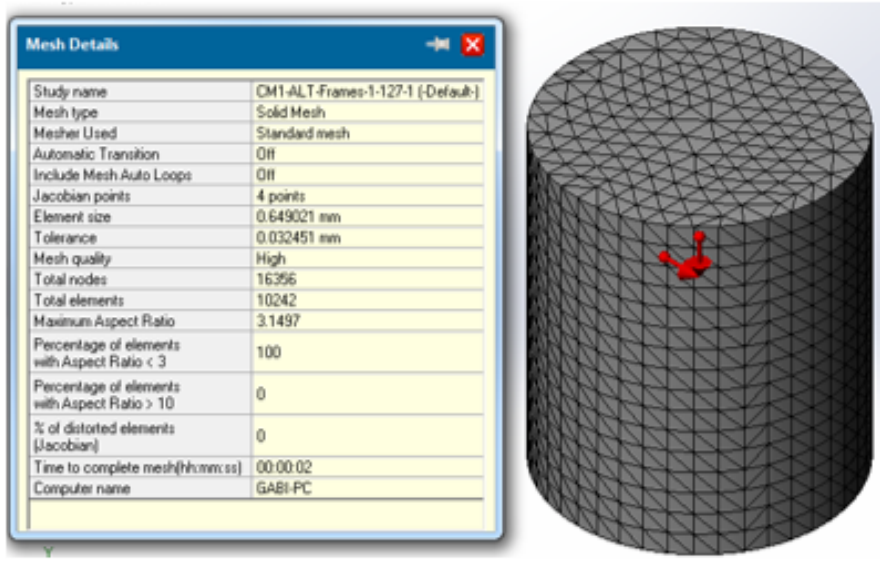

Fig. 8 Meshed model and mesh details

Table1

CHARACTERISTICS OF MATERIALS USED IN FINITE ELEMENT ANALYSIS [25-28]

\begin{tabular}{|c|c|c|c|c|}
\hline & Solidex & Artglass & BelleGlass & Targis \\
\hline Elastic Modulus, $\mathrm{N} / \mathrm{mm}^{2}$ & $15.61 \mathrm{E} 003$ & $14.03 \mathrm{E} 003$ & $21.55 \mathrm{E} 003$ & $\begin{array}{l}19.48 \\
\text { E003 }\end{array}$ \\
\hline Poisson's Ratio & 0.27 & 0.28 & 0.22 & 0.26 \\
\hline Shear Modulus, $\mathrm{N} / \mathrm{mm}^{2}$ & $6.7 \mathrm{E} 003$ & $6 \mathrm{E} 003$ & $8.9 \mathrm{E} 003$ & $6.9 \mathrm{E} 003$ \\
\hline Mass Density, $\mathrm{kg} / \mathrm{m}^{3}$ & 1680 & 2400 & 2500 & 2700 \\
\hline Tensile Strength, N/mm ${ }^{2}$ & 40 & 38 & 41 & 44 \\
\hline $\begin{array}{l}\text { Compressive Strength, } \\
\mathrm{N} / \mathrm{mm}^{2}\end{array}$ & 206.7 & 224 & 163.02 & 163.39 \\
\hline Yield Strength, $\mathrm{N} / \mathrm{mm}^{2}$ & 76.95 & 94.76 & 132.48 & 111.23 \\
\hline Filler size & $\begin{array}{l}1 \mu \mathrm{m} \text { silicon } \\
\text { dioxide, } \\
\text { aluminium oxide }\end{array}$ & $\begin{array}{l}1 \mu \mathrm{m} \text { barium } \\
\text { glass, colloidal } \\
\text { silica }\end{array}$ & $\begin{array}{c}25 \mu \mathrm{m} \text { particles (blend of resin, } \\
\text { barium glass and discrete nanofiller) } \\
0.4 \mu \mathrm{m} \text { structural filler and small } \\
\text { discrete silica nanoparticles }\end{array}$ & $\begin{array}{c}30 \mathrm{~nm}-1 \\
\mu \mathrm{m} \\
\text { barium } \\
\text { glass, } \\
\text { silicon } \\
\text { dioxide }\end{array}$ \\
\hline Filler content ( $\%$ vol) & $53 \%$ & $68 \%$ & $87 \%$ & $55 \%$ \\
\hline
\end{tabular}

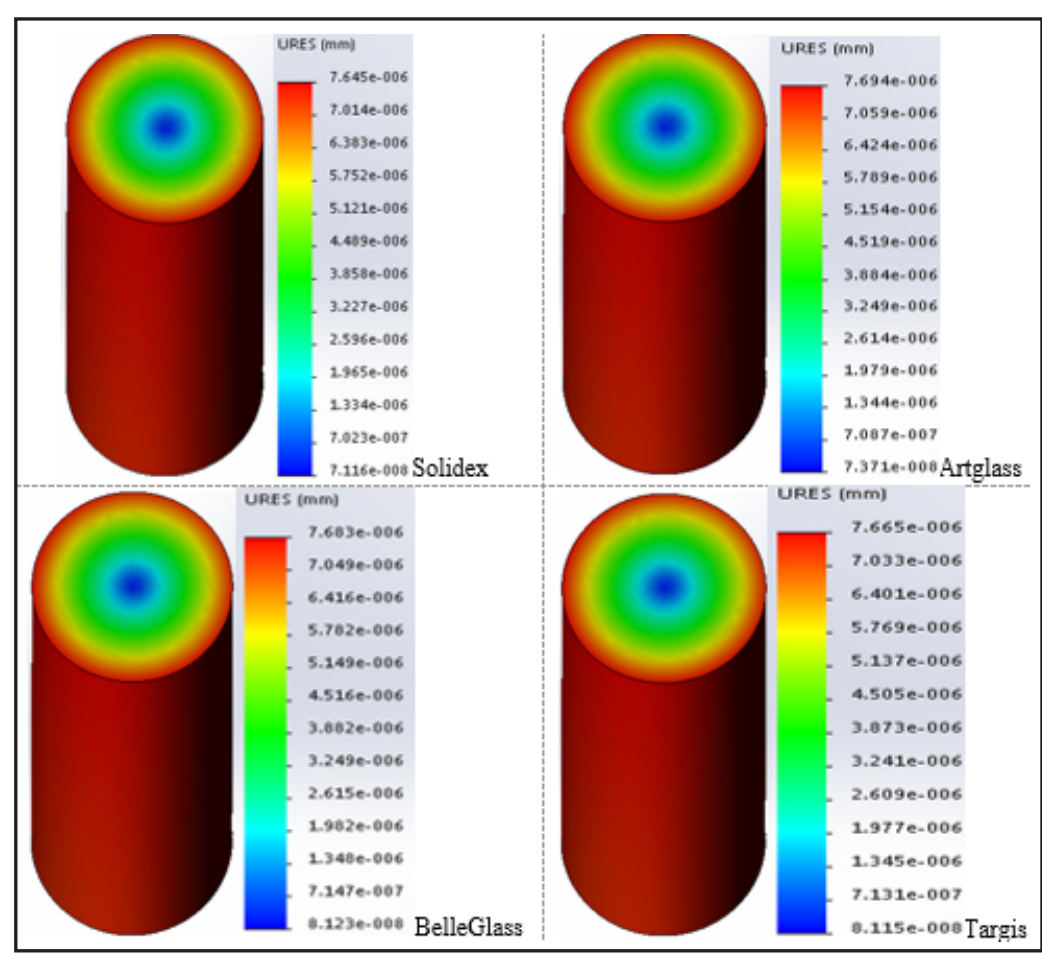

Fig. 9. The values of displacements in the four analyzed biocomposite materials models

the geometric model in which the analysed physical size has the value specified in the chromatic legend on the right side of the display.

For modelled and analysed workpiece models, are presented below the results of the simulation in Solid Works. Thus, in figure 9 the values of the displacements occurring in the four types of materials are displayed during the previously defined loads.
Analysing these data, it can be seen that the largest displacements of the nodes in the structure of the workpiece appear on its exterior, the maximum values of the displacements being of $7.645 \cdot 10^{-6} \mathrm{~mm}$ in case of Solidex, $7.694 \cdot 10^{-6} \mathrm{~mm}$ in case of Artglass, $7.683 \cdot 10^{-6}$ in case of BelleGlass and $7.665 \cdot 10^{-6} \mathrm{~mm}$ in case of Targis.

In figure 10 and figure 11 the values of the equivalent stresses are presented of the four types of materials under 


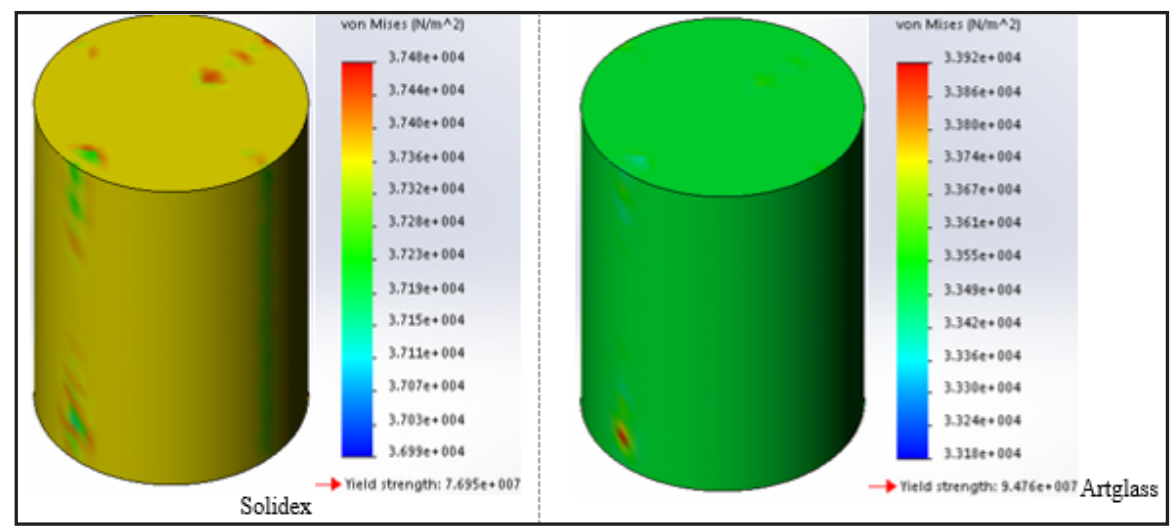

Fig.10. Values of the equivalent stresses by the von Mises criterion of the four analysed biocomposite material models (for Solidex and Artglass)

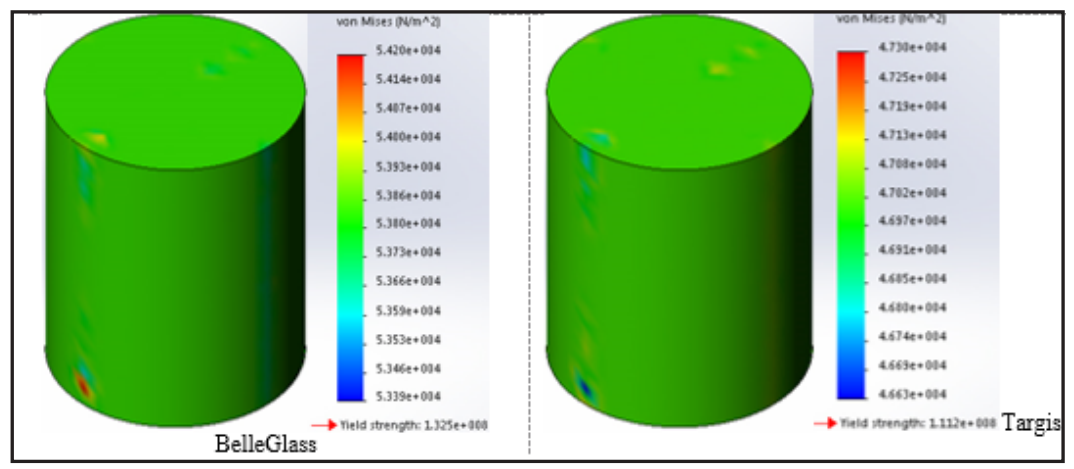

Fig.11. Values of the equivalent stresses by the von Mises criterion of the four analysed biocomposite material models (for BelleGlass and Targis)

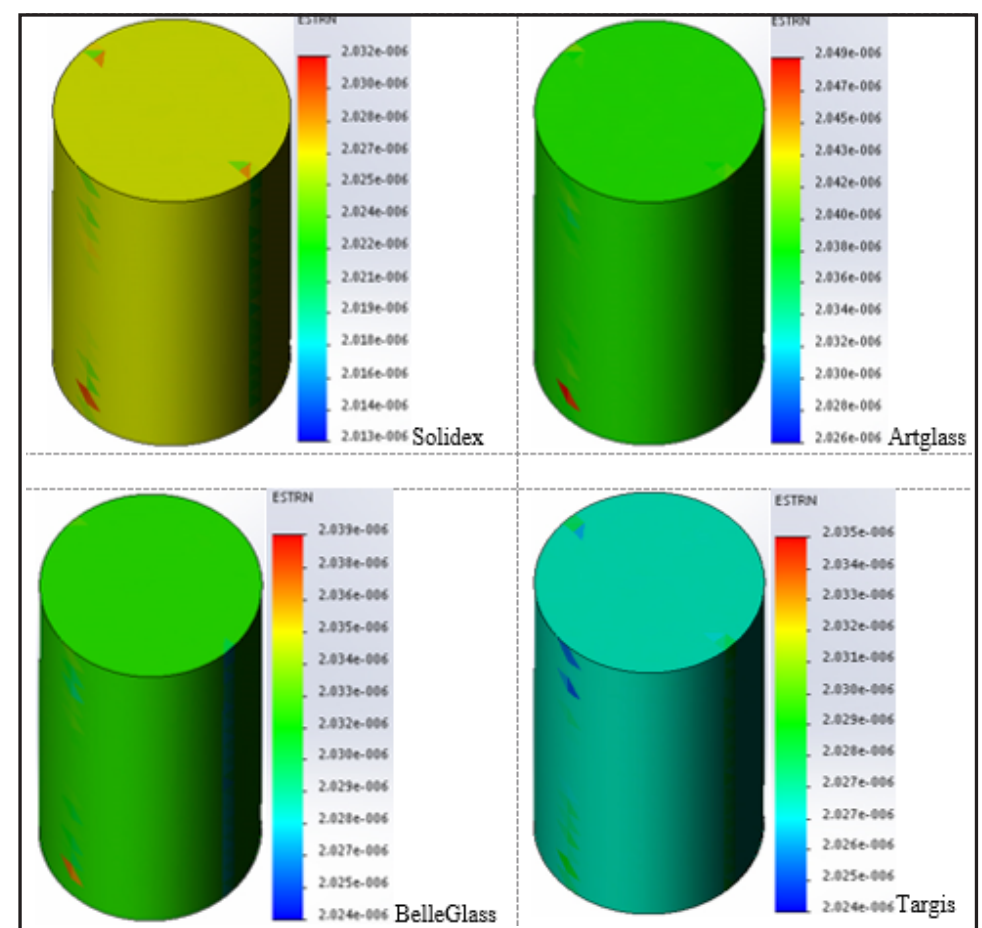

Fig.12. The values of the equivalent strain occurring in the four analysed biocomposite materials models

the action of loads, stresses calculated by the von Mises criterion.

Analysing this figures we can see that in the structure of the workpiece stress concentrating points appear, values of the equivalent stresses of von Mises created in these points being of $3.748 \cdot 10^{4} \mathrm{~Pa}$ for Solidex, 3.392:10 $\mathrm{Pa}$ for Artglass, $5.42 \cdot 10^{4} \mathrm{~Pa}$ for BelleGlass and $4.73 \cdot 10^{4} \mathrm{~Pa}$ for Targis. By ignoring these points, it can be noticed that residual tensions occur in the structure of the workpiece, tensions that can produce microfractures even from the moment of polishing.

Analysing figure 12 we can observe the values of the equivalent strain occurring in the four types of material following the loads it is subjected to. Thus, the maximum equivalent strain occurs at the same stress concentrating points, value of the deformation being of $2.032 \cdot 10^{-6}$ for
Solidex, 2.049 $10^{-6}$ for Artglass, $2.039 \cdot 10^{-6}$ for Belleglas and $2.036 \cdot 10^{-6}$ for Targis, while the minimum equivalent strain for the four material types have values below $2.026 \cdot 10^{-6}$.

\section{Conclusions}

It can be said that both the values of the equivalent stresses calculated by the von Mises criterion and the equivalent strain for all four types of analysed materials are close. Still, from figures 10 and 11, it can be seen that the average values are quite different. Thus, in the case of Solidex composite, these average values are quite high, most stress concentrating points appearing more stress concentrating points. In these points may appear microfractures that only shorten the life of the material. Under simulation conditions, the Targis composite behaved 
best, in its structure emerging the fewest concentrating points of tension.

The data in the article is particularly importantfor dental technicians, who performs the workpiece processing. They must understand that there may be accumulated residual stresses in the material to be processed even from the moment of polishing, thus lowering the durability of the finished product. During polishing, it is necessary to be properly correlated the speed of dental bur with the force of pressing on the workpiece. The dental bur should notbe forced to work faster by manipulation with an excessively high pushing force. This can cause damages including to the polishing tools, notonly to material that can accumulate remaining tensions.

\section{References}

1.NIELSEN, M.S., SØRENSEN, B.F., ALMDAL, K., Interface structure and strength in model dental resin composites, Kgs. Lyngby, Technical University of Denmark, 2011

2.POWERS, J.M., SAKAGUCHI, R.L., Resin Composite Restorative Materials, Craig's Restorative Dental Materials, $12^{\text {th }}$ ed. United States of America: Mosby Elsevier, 2006, p.189-212.

3.SKRTIC, D., ANTONUCCI, J.M., MCDONOUGH, W.G., LIU, D.W., Effect of chemical structure and composition of the resin phase on mechanical strength and vinyl conversion of amorphous calcium phosphate-based composites, Journal of biomedical materials research. Part A, 68(4), 2004, p.763-772.

4.DYER, S.R., LASSILA, L.V., JOKINEN, M., VALLITTU, P.K., Effect of fiber position and orientation on fracture load of fiber-reinforced composite, (2004), Dental Materials, 20(10), 2004, p. 947-955.

5.PETERSEN, R.C., Discontinuous fiber-reinforced composites above critical length, J ournal of Dental Research, 84(4), 2005, p.365-370

6.BEUN, S., GLORIEUX, T, DEVAUX J., VREVEN, J., LELOUP, G., Characterisation of nanofilled compared to universal and microfilled composites, Dental Materials, vol.23, 2007, p.51-59

7.FERRACANE, J.L., Resin composite - state of the art, Dental Materials, 27(1), 2011, p.29-38

8.MCCABE J.F., WALLS A.W.G., Applied Dental Materials, Oxford, Wiley-Blackwell, 2008

9.ANGKER, L, SWAIN, M.V., Nanoindentation: Application to dental hard tissue investigations, Materials Research, 21(8), 2006, p.18931905.

10.CALLISTER, JR., W.D., Materials science and engineering an introduction, 7th edition, John Wiley \& Sons, Inc., 2007.

11.NAYYER, M., ZAHID, S., HASSAN, S.H., MIAN, S.A., MEHMOOD, S., KHAN, H.A., KALEEM, M., ZAFAR, M.S., KHAN, A.S., Comparative abrasive wear resistance and surface analysis of dental resin-based materials, European J ournal of Dentistry, 12(1), 2018, p.57-66.

12.BRAGA, R.R., BALLESTER, R.Y., FERRACANE, J.L., Factors involved in the development of polymerization shrinkage stress in resincomposites: a systematic review. Dental Materials, 21(10), 2005, p.962970.

13.SCHNEIDER, L.F., CAVALCANTE, L.M., SILIKAS, N., Shrinkage Stresses Generated during Resin-Composite Applications: A Review, J ournal of Dental Biomechanics, 2010, p.1-14

14.FERRACANE, J.L., Hygroscopic and hydrolytic effects in dental polymer networks, Dental Materials, 22(3), 2006, p.211-222.

15.SIDERIDOU, I., TSERKI, V., PAPANASTASIOU, G., Study of water sorption, solubility and modulus of elasticity of light-cured dimethacrylate-based dental resins, Biomaterials, vol.24, 2003, p.655665.

16.GALVAO M.R., COSTA S., VICTORINO K.R., RIBEIRO A.A., MENEZES F.C.H., RASTELLI, A.N.S, et al., Influence of light guide tip used in the photoactivation on degree of conversion and hardness of one nanofilled dental composite. Laser Physics vol.20, 2010, p.2050-2055 17.VAN MEERBEEK, B., PEUMANS, M., POITEVIN, A., MINE, A., VAN ENDE, A., NEVES, A., DE MUNCK, J., Relationship between bondstrength tests and clinical outcomes, Dental Materials, 26(2), 2010, e100-e121

18.ZHOU, J , TAN, J ", CHEN, L, LI, D, TAN, Y., The incorporation of chlorhexidine in a two-step self-etching adhesive preserves dentin bond in vitro. Journal of dentistry, 37(10), 2009, p.807-812

19.DAVIDSEN, C., ANDRE, J.F., GIET, D., Van MEERBEEK, M., Patientphysician electronic communication, Revue medicale de Liege, vol.66, 2011, p.417-423

20.CADENARO, M., ANTONIOLLI, F., SAURO, S., TAY, F.R., DI LENARDA, R., PRATI, C., BIASOTTO, M., CONTARDO, L., BRESCHI, L., Degree of conversion and permeability of dental adhesives, European Journal of Oral Sciences, vol.113, 2005, p.525-530

21.HEBLING, J., PASHLEY, D.H., TJADERHANE, L., TAY, F.R., Chlorhexidine arrests subclinical degradation of dentin hybrid layers in vivo, J ournal of Dental Research, vol. 84, 2005, p.741-746

22.MCCABE, J.F., MOLYVDA, S., ROLLAND, S.L., RUSBY, S., CARRICK, T.E., Two- and three-body wear of dental restorative materials. International Dental Journal, vol. 52, 2002, p.406-416.

23.BORS, A., ANTONIAC, I., COTRUT, C., ANTONIAC, A., SZEKELY, M., Surface analysis of contemporary aesthetic dental filling materials after storage in erosive solutions, Mat. Plast., 53, no. 4, 2016, p.38-41 24.DRUMMOND, J.L., Degradation, fatigue, and failure of resin dental composite materials, J ournal of Dental Research, 87(8), 2008, p.710719.

25.PAPADOGIANNIS, Y., LAKE,S R.S., PALAGHIAS, G., HELVATJ OGLUANTONIADES, M., PAPADOGIANNIS, D., Fatigue of packable dental composites. Dental Materials, vol.23, 2007, p.235-242.

26.AGHAZADEH MOHANDESI, J., RAFIEE, M.A., BARZEGARAN, V., SHAFIEI, F., Compressive fatigue behavior of dental restorative composites, Dental Materials J ournal, 26(6), 2007, p.827-837

27.KAMEYAMA, A., NAKAZAWA, T., HARUYAMA, A., HARUYAMA, C., HOSAKA, M., HIRAI, Y., Influence of finishing/polishing procedures on the surface texture of two resin composites, The Open Dentistry J ournal, no.2, 2008, p.56-60.

28.NAGEM FILHO, H., D'AZEVEDO FORTES SOARES, M,T, NAGEM, H.D., PÁTARO MARSOLA, F., Surface roughness of composite resins after finishing and polishing, Brazilian Dental J ournal, 2003, vol.14, Is.1, p.37-41.

29.ROEDER, L.B., POWERS, J.M., Surface roughness of resin composite prepared by single-use and multi-use diamonds, American J ournal of Dentistry, 2004, 17(2), p.109-112

30.LUTZ, F., SETCOS, J.C., PHILLIPS, R.W., New finishing instruments for composite resins, Journal of the American Dental Association, 1983, vol.107, p.575-580.

31.REIS, A.F., GIANNINI, M., LOVADINO, J.R., AMBROSANO, G.M., Effects of various finishing systems on the surface roughness and staining susceptibility of packable composite resins, Dental Materials, 2003, 19(1), p.12-18.

32.BERASTEGUI, E., CANALDA, C., BRAU, E., MIGUEL, C., Surface roughness of finished composite resins, The Journal of Prosthetic Dentistry, 1992, 68(5), p.742-749.

33.BOGHOSIAN, A.A., RANDOLPH, R.G., JEKKALS, V.J., Rotatory instrument finishing of microfilled and small-particle hybrid composite resins, Journal of the American Dental Association, 1987, 115, p.299301.

JUNG, M., BAUMSTIEGER, M., KLIMEK, J., Effectiveness of diamondimpregnated felt wheels for polishing a hybrid composite, Clinical Oral Investigations, 1997, 1(2), p.71-76.

$\overline{\text { Manuscript received } 15.06 .2018}$ 